\title{
Fluorodeoxyglucose Positron Emission Tomography for Giant Cell Arteritis
}

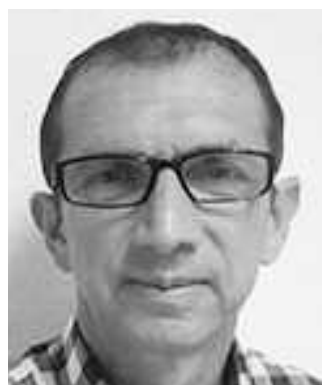

Up to 20 years ago, giant cell arteritis (GCA) was regarded as a form of vasculitis that involved almost solely the cranial arteries in elderly people, and when undiagnosed and untreated, could lead to blindness. Involvement of other arteries in GCA, such as the coronary arteries or the ascending aorta, manifested by myocardial infarction or aortic rupture, respectively, was regarded as rather exceptional ${ }^{1}$.

With the use of $18 \mathrm{~F}$-fluorodeoxyglucose positron emission tomography (FDG-PET) in patients suspected of having GCA, this concept changed. We now know that more than half of biopsy-proven patients with GCA have clear but asymptomatic inflammation of their aorta; up to $75 \%$ of the subclavian arteries are involved in this form of large-vessel vasculitis $(\mathrm{LVV})^{2}$. FDG uptake patterns on PET of patients with GCA and Takayasu arteritis in fact are almost identical (because the temporal artery itself cannot be visualized on PET owing to the small size of the artery, its superficial location, and the vicinity of the FDG-consuming brain). The question now arises whether these are 2 different diseases or manifestations of the same disease attacking people at different ages ${ }^{3}$.

The American College of Rheumatology classification criteria for GCA date from 1990, the pre-PET era, and their main emphasis is on cranial symptoms ${ }^{4}$. They are much less suited for the large-vessel variant of GCA largely unknown at that time, with fever, weight loss, or limb claudication as the main manifestations ${ }^{5}$. Although the criteria were never intended to be used as diagnostic criteria, but to classify different forms of vasculitis (hence, a proven vasculitis is a prerequisite to their use), the fact is that they are frequently used that way, not only in the clinic but also in scientific publications.

Research on the use of PET in LVV has long been hampered by the high costs and low availability of this technique in countries such as the United States, where it was mainly reserved for oncological purposes. However, in recent multinational studies such as the GiACTA trial, a randomized, double-blind, placebo-controlled trial looking at the effect of an interleukin 6 receptor blocker as a possible new treatment for GCA, almost $40 \%$ of the patients were included on the basis of a positive PET scan and not of a positive temporal artery biopsy $(\mathrm{TAB})^{6,7}$. This reflects the increasing use of PET for the diagnosis of GCA in countries where this technique is readily available. TAB, a minimally invasive technique, remains the gold standard for the cranial form of GCA, but is of far less use for the large-vessel variant, because the temporal arteries are much less involved in these patients.

This brings us to a problem frequently encountered in daily practice: how long does it take before you can get a PET scan for your patient suspected of GCA, and can you postpone steroid treatment that long? Indeed, it has been shown that prior steroid intake will dampen vascular FDG uptake in LVV and hence will lower its diagnostic potential ${ }^{8}$. It is not known how many days of steroid treatment and which dose is tolerated. For TAB, one assumes that the diagnostic yield will not fall dramatically when the biopsy is done during the first week of steroid treatment ${ }^{9}$.

In the article by Clifford, et al in this issue of The Journal ${ }^{10}$, the authors report on their experience with FDG-PET in patients with GCA already treated with steroids (mean cumulative prednisone exposure of $645 \mathrm{mg}$ after a mean of 11.9 days of treatment). I presume this is what happens if you ask for a PET scan in your clinic and you have no priority; I can even imagine that waiting lists can be much longer. The authors found that even after this period of steroid treatment, mean PET/CT scores were higher in patients with GCA compared to controls and that the optimal cutoff for distinguishing GCA cases from controls was a total PET/CT score of 9. I am afraid, however, that used in this way, a PET scan has no additional diagnostic value in daily clinical practice, because a sensitivity of $71.4 \%$ and a specificity of $64.3 \%$ are far too low for that purpose. Moreover,

See PET/CT in newly diagnosed GCA, page 1859

Personal non-commercial use only. The Journal of Rheumatology Copyright @ 2017 . All rights reserved. 
there was no difference between PET scores in their TAB-negative patients compared to their controls. In TAB-positive patients, one does not need a PET scan to make the diagnosis, but in TAB- negative patients, PET is probably the last attempt to come to a confirmed diagnosis. Hampering this technique by the immediate start of steroid treatment is not wise. The authors state that it is unethical to withhold glucocorticoid treatment in patients with suspected GCA. Is this really always the case? I agree that one should not postpone steroid treatment in patients with any visual symptoms or with jaw claudication, but should one really start steroids promptly when there is only some headache with polymyalgia rheumatica complaints, or when there is a suspicion of GCA in patients with fever, weight loss, and highly increased inflammatory variables? In fact, when there are visual symptoms such as amaurosis fugax, one should not start with $40 \mathrm{mg}$ or $60 \mathrm{mg}$ prednisone/day, but with something like 500-1000 mg intravenously for up to 3 days, and the effect of this massive steroid dose on PET results is completely unknown. If one wants to include PET as a diagnostic tool for GCA in one's clinical practice, then there should be an agreement with the nuclear medicine department that suspicion of GCA is regarded as an urgent and priority indication for PET, and PET should be performed within the next 3 or 4 days. I would strongly argue not to start steroids in the meantime (with the exception of visual symptoms and probably jaw claudication, as stated above) because an unconfirmed diagnosis of a clinical suspicion of GCA leaves the patient and the doctor with the unresolved question of how to continue steroids in the next months or years.

I realize that some $\mathrm{TAB}$ are also not unequivocally positive or negative (e.g., when there is only cellular infiltration of the adventitia of the vessel or of the vasa vasorum or of a small side branch) ${ }^{11}$, but I prefer to have the number of doubtful PET results as low as possible, and therefore we have to avoid as much as possible interference from steroids. In the clinic, I consider a PET scan as positive for vasculitis if everyone can see the increased vascular FDG uptake with the naked eye without having to count the pixels and comparing them to a background area.

Then the question remains: what is the gold standard for the diagnosis of GCA? When the TAB is positive, then it is easy. In all other cases, it is the clinical opinion of the experienced clinician who takes into account all available data (symptoms, clinical examination, biochemical data, PET results or results of other imaging techniques such as ultrasound or magnetic resonance imaging, and response to therapy) and this after a minimum followup of 6 months.
DANIEL BLOCKMANS, MD, PhD,

Katholieke Universiteit Leuven,

General Internal Medicine,

Leuven, Belgium.

Address correspondence to Prof. Dr. D. Blockmans, Katholieke Universiteit Leuven, General Internal Medicine, Herestraat 49, Leuven B-3000, Belgium.E-mail: daniel.blockmans@uzleuven.be

\section{REFERENCES}

1. Evans JM, O'Fallon WM, Hunder GG. Increased incidence of aortic aneurysm and dissection in giant cell (temporal) arteritis. A population-based study. Ann Intern Med 1995;122:502-7.

2. Blockmans D, De Ceuninck L, Vanderschueren S, Knockaert D, Mortelmans L, Bobbaers H. Repetitive 18F-fluorodeoxyglucose positron emission tomography in giant cell arteritis: a prospective study of 35 patients. Arthritis Rheum 2006;55:131-7.

3. Grayson PC, Maksimowicz-McKinnon K, Clark TM, Tomasson G, Cuthbertson D, Carette S, et al. Distribution of arterial lesions in Takayasu's arteritis and giant cell arteritis. Ann Rheum Dis 2012;71:1329-34.

4. Hunder GG, Bloch DA, Michel BA, Stevens MB, Arend WP, Calabrese LH, et al. The American College of Rheumatology 1990 criteria for the classification of giant cell arteritis. Arthritis Rheum 1990;33:1122-8.

5. Brack A, Martinez-Taboada V, Stanson A, Goronzy JJ, Weyand CM. Disease pattern in cranial and large-vessel giant cell arteritis. Arthritis Rheum 1999;42:311-7.

6. Tuckwell K, Collinson N, Dimonaco S, Klearman M, Blockmans D, Brouwer E, et al. Newly diagnosed vs relapsing giant cell arteritis: baseline data from the GIACTA trial. Semin Arthritis Rheum 2017;46:657-64.

7. Stone JH, Tuckwell K, Dimonaco S, Klearman M, Aringer M, Blockmans D, et al. Trial of tocilizumab in giant-cell arteritis. N Engl J Med 2017;377:317-28.

8. Blockmans D, Maes A, Stroobants S, Nuyts J, Bormans G, Knockaert D, et al. New arguments for a vasculitic nature of polymyalgia rheumatica using positron emission tomography. Rheumatology 1999;38:444-7.

9. Narváez J, Bernad B, Roig-Vilaseca D, García-Gómez C, Gómez-Vaquero C, Juanola X, et al. Influence of previous corticosteroid therapy on temporal artery biopsy yield in giant cell arthritis. Semin Arthritis Rheum 2007;37:13-9.

10. Clifford AH, Murphy EM, Burrell SC, Bligh MP, MacDougall RF, Heathcote JG, et al. Positron emission tomography/computerized tomography in newly diagnosed patients with giant cell arteritis who are taking glucocorticoids. J Rheumatol 2017;44:1859-66.

11. Le Pendu C, Meignin V, Gonzalez-Chiappe S, Hij A, Galateau-Sallé F, Mahr A. Poor predictive value of isolated adventitial and periadventitial infiltrates in temporal artery biopsies for diagnosis of giant cell arteritis. J Rheumatol 2017;44:1039-43.

J Rheumatol 2017;44:1763-4; doi:10.3899/jrheum.170966 